\title{
Study on optimization design of building water supply and drainage projects
}

\author{
Yunzhao Fan ${ }^{1, \text { a }}$, Tianpeng Wang ${ }^{2, \mathrm{~b}}$, Jinwei Lei ${ }^{2, \mathrm{c}}$ and Chong $\operatorname{Tan}^{1, \mathrm{~d}}$ \\ ${ }^{1}$ Gansu Yinguang-Juyin Chemical Limited Company, Baiyin 730900, China \\ ${ }^{2}$ Gan Su Yin Guang Chemical Industry Group Co.LTD Enengetic Matenrials Subcompany , Baiyin \\ 730900, China

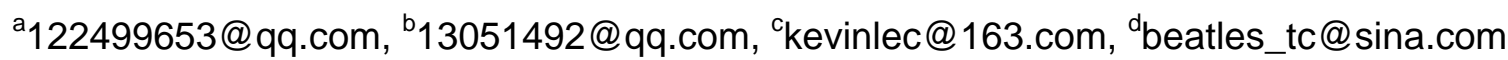

Keywords: building, water supply drainage project, optimization

\begin{abstract}
With the continuous improvement of people's living standards, there has been a higher requirement of buildings' construction level. In order to create a favorable living space, the current construction departments should emphasize on optimization of water supply and drainage system design during the implementation process of projects. Based on that, irregular construction behaviors should be avoided in the case of influencing people's overall quality of life. Proceeding from the analysis of the importance of the water supply and drainage system, this paper expounds on relevant issues of water supply and drainage, aiming at pushing forward further development of the contemporary building industry.
\end{abstract}

\section{Introduction}

Currently, water supply and drainage project design still has some defects. In order to enhance competitiveness in the market, the building industry should optimize its project design models through the application of automation, communications and other new techniques. By doing so, it can improve its overall project construction quality and achieve the optimal project construction state. Below is a detailed exposition of strategies to optimize water supply and drainage design, which attempts to provide useful references for sustainable development of the modern building industry.

\section{Importance of water supply and drainage to building construction}

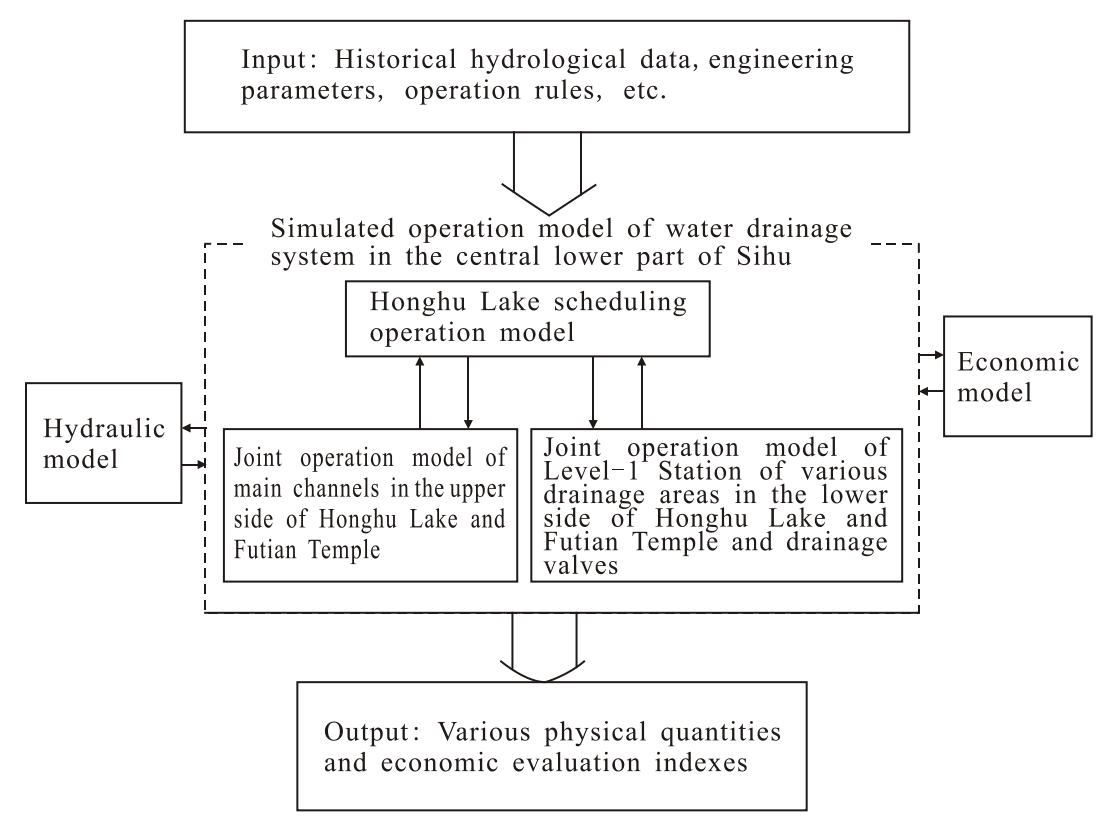

Fig. 1 Sihu water supply and drainage 
Fig. 1 shows the water supply and drainage system design model, which emphasizes on the importance of water supply and drainage during the project construction process. Against the backdrop of rapid social development, China's building industry should realize the important role of reclaimed water system, landscape system and automatic sprinkler system in construction projects, because they indirectly decide the overall building quality and provide adequate water resources for residents' production and living. Besides, water supply and drainage is an important part of construction projects, which can influence the completeness of projects to some extent. In view of that, construction units should deepen the application of design calculation methods during the project implementation process.

$$
H j=\xi \frac{V j^{2}}{2 g}+0.00107 L \frac{V j^{2}}{d_{j}{ }^{1.3}}
$$

Based on the reasonable design calculation methods, the construction quality is ensured and residents' water demands are satisfied.

II. Optimization of building water supply and drainage project design to promote social development

\section{Optimization of water supply and drainage methods.}

In order to meet requirements of building design quality during the social development process, contemporary construction units should choose suitable water supply and drainage methods during the project implementation process, such as water supply based on the air-pressure tank. Besides, facilities, including the air-pressure tank and the pumping unit, can be equipped so as to improve the overall project quality. Based on that, automatic water resources adjustment can be achieved. Besides, the water supply method boasts the advantage of a low load, so its application should be enhanced. Apart from the selection of water supply and drainage, attention should also be paid to the application of the following equation:

$$
Q 1=\sum q_{i} N_{i}\left(m^{3} / d\right)
$$

The overall domestic water demand in the residential area is calculated. During the calculation process, it is clarified that qi and $\mathrm{Ni}$ stand for the domestic water consumption and the number of people requiring water consumption. Based on the data integration, the optimal water supply and drainage design status can be achieved. Besides, during the construction process of public buildings, the equation should be properly used to meet project design conditions. In order to improve the overall water supply and drainage design level, the contemporary building industry should pay attention to the application of the method of pressure reduction and water supply in different areas. Through the water pump, water resources can be immediately sent to the top water tank to reduce the area covered by the overall water facilities, and save the overall investment cost [1].

\section{Optimized design of the water drainage system.}

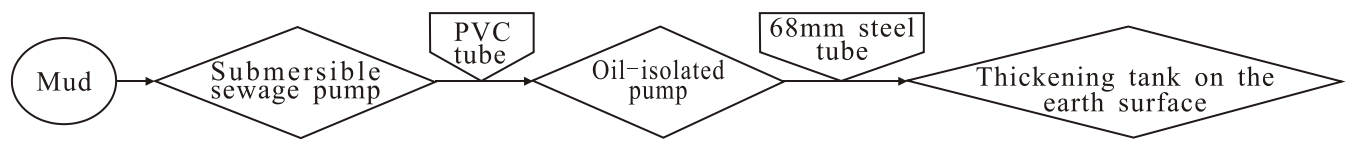

Fig. 2 Borehole operation water drainage system

Fig. 2 shows the borehole operation water drainage system design flow, from which it can be seen that water drainage system design has a close bearing on the overall project quality. In view of it, the contemporary construction units should attach great importance to it. Besides, emphasis should also be put on the application of the equation to work out unpredicted water quantity based on optimized design of water drainage system. The equation is shown below:

$$
Q_{5}=(0.15-0.25) X\left(Q_{1}+Q_{3}+Q_{4}\right)+\mathrm{a} Q_{2}\left(m^{3} / d\right)
$$

According to the above equation, the leakage of the pipeline network can be learned. Based on the calculation design, the unpredicted water quantity is $15 \%$ of the monthly highest water consumption. Set a as the water quantity coefficient to control the practical design status of the 
water drainage system, and to conduct proper optimization. Besides, based on the optimized water drainage system design, the fire demand can be worked out:

$$
Q 5=\sum q_{s} N_{s}(1 / s)
$$

According to the above equation, relevant design data can be obtained. However, designers should make it clear that qs and Ns stand for the water demand for one fire extinguishment and the number of fire disasters, and the water drainage system design can be standardized based on that. Besides, emphasis should be put on the treatment of noise issues during the design process. In other words, the drainage pipeline should be put in a suitable place and equipped with the silencer to avoid negative influence caused by irregular design behaviors on people's quality of life.

\section{Optimized design of the water supply system.}

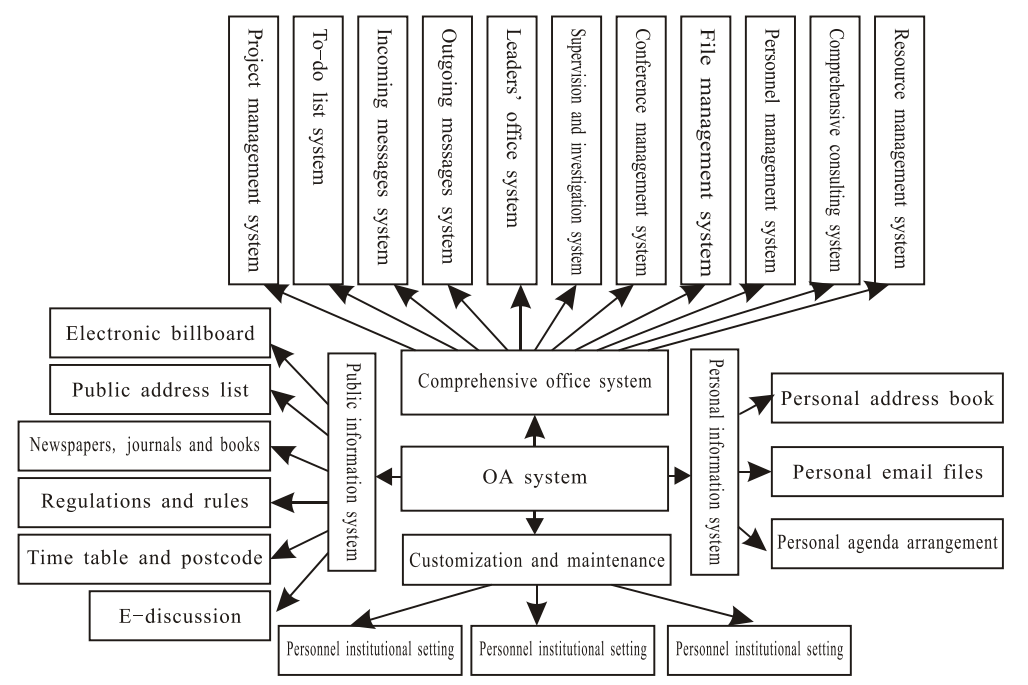

Fig. 3 Automatic scheduling system of water supply and drainage

Fig. 3 shows the automatic scheduling system of water supply and drainage, from which it can be seen that the contemporary construction units emphasize on the application of automatic techniques. In view of it, designers should sharpen their technical application awareness during the water supply system design process, and pay attention to the solution of noise issues during the optimization process. In other words, there should be some distance for the water drainage pipeline away from the toilet and the kitchen in the house on the one hand; on the other hand, the source pressure of water supply should be properly controlled to avoid noises from impairing residents' overall quality of life. Besides, the following equation should be put into use during the indoor water supply system design:

$$
Q_{4}=\sum q_{1} N_{1}\left(m^{3} / d\right)
$$

The equation to calculate the greening water demand is used to integrate the overall water supply. Based on that, people can embrace a favorable living environment and their quality of life can be improved [2].

\section{Conclusions}

To sum up, some construction units are still faced with problems, such as irregular design methods, during the water supply and drainage system design process, which can influence the full play of the performance of the water supply and drainage system. In view of the status quo, the contemporary building industry should alleviate prominent problems under the traditional building design model through optimized design of water supply system, water drainage system and water supply and drainage system. By doing so, the optimal building design status can be achieved, and the overall building planning level can be improved to meet the contemporary social development conditions. 


\section{References}

[1] LU Yanqin, XU Liwei \& WEI Caichun. Optimized course teaching of "Building Water Supply and Drainage Project" based on the course case teaching design [J]. Theory and Practice of Contemporary Education, 2012, 21 (11): 103-105.

[2] ZUO Meimei, DING Zhao, WU Tian, et al. Teaching reform and practice of graduation design for "Building Water Supply and Drainage Project" [J]. China Electric Power Education, 2011, 32 (20): 148-149. 